\title{
Metastable phase in binary and ternary 12-carat gold alloys at low temperature
}

Imene Lamiri ${ }^{1,2}$, Mohammed S.M. Abdelbaky ${ }^{2}$, Djamel Hamana ${ }^{1}$, Santiago GarcíaGranda $^{2}$

1-Research Unit Materials Science and Applications, Mentouri University and National Polytechnic High School of Constantine, 25000 Constantine, Algeria.

2- Department of Physical and Analytical Chemistry, University of Oviedo-CINN, 33006 Oviedo, Spain.

Email:saidmohammed.uo@uniovi.es

\section{Abstract}

Low temperature phase transitions in 12-carat gold alloys have been investigated for binary $\mathrm{Au}-\mathrm{Cu}$ and ternary $\mathrm{Au}-\mathrm{Cu}-\mathrm{Ag}$ compositions. The thermal analyses investigations using differential scanning calorimetry (DSC) and the dilatometry were performed in the $50-300^{\circ} \mathrm{C}$ temperature range in order to detect the structural transformations. The thermal analyses were carried out on annealed samples at $700^{\circ} \mathrm{C}$ for two hour followed by water quenching. They reveal an important new reaction for both used compositions and both thermal techniques confirm each other. This reaction has been assessed as pre-ordering reaction. SEM and STM imaging were performed on annealed samples at $700^{\circ} \mathrm{C}$ for two hours and water quenched followed by a heating from room temperature up to the temperature of the new peaks obtained in the thermal study. The imaging reveals the relationship between the pre-ordering reaction and the surface aspect presented in the fact of dendrite precipitates. A series of SEM observation have been performed in order to follow the kinetic of the observed precipitates by the way of several series of heating up, from 140 to $220^{\circ} \mathrm{C}$ for the binary composition and from 100 to $180^{\circ} \mathrm{C}$ for the ternary composition. Furthermore, this study shows that the silver accelerates the ordering reaction.

Keywords: DSC, Dilatometry, SEM, STM, Copper oxide. 


\section{Introduction}

It is well known that order-disorder transitions produces significant effect on the alloy properties $[1,2]$. The debate on features, characteristic of constituent atoms, which drive ordering in different systems, has been going on for well over half a century [3]. Transition metal and noble metal binary intermetallic $L 1_{2}$ alloys received considerable attention in recent years due to their relations with many technologically important materials having improved mechanical, electronic, magnetic and catalytic properties [4].

The AuCu system is one of the earliest systems for which several order-disorder and order-order type transformations were established [5,6]. The gold-copper system has extensively been studied for about 150 years. This material appears to be a testing ground for different approaches and models that are aimed to describe phase changes in stoichiometric alloys [7]. This system is of great importance for jewelry and microelectronics [8].

According to the binary phase diagram, the stoichiometric $\mathrm{AuCu}_{3}$ displays one direct

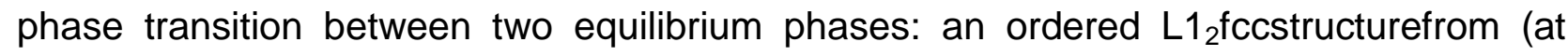
least) room temperature to $390^{\circ} \mathrm{C}$ and a disordered fcc $\mathrm{A} 1$ phase from $390^{\circ} \mathrm{C}$ up to the melting [9-11]. The Au-Cu-Ag is an important ternary system, acting as the basic phase diagram for an understanding of gold dental alloys, has been studied for the past century $[12,13]$. The ternary 12-carat system exhibit several phase compositions that depend on the weight participation of the added elements to gold as reported in ref [12-15]. And it displays a variety of diffusional phase transformations including compositional demixing and ordering $[12,13]$. To our knowledge, only a few studies have investigated the phase transformation in 12-carat systems especially the ternary composition.

A new pre-ordering reaction that precedes the formation of the ordered phase in the equiatomic $\mathrm{Au}-\mathrm{Cu}$ system occurs at low temperature, and it has been observed for the first time by Hamana et al [16]. The main aim of our study is to check the presence of such reaction in 12-carat binary and ternary gold alloys. Therefore, one binary (Au-50 wt.\%.Cu-50wt.\%) and one ternary (Au-15wt.\%.Cu-35wt.\%.Ag) compositions are chosen. The thermal results were unexpected. The study is completed with a trial to identify the nature and the origin of the new meta-stable phase that appears in very specific conditions of temperature. That can lead to new properties then new exploit of these systems at low temperature. 


\section{Materials and methods}

\subsection{Preparation of the alloys}

$\mathrm{Au}-\mathrm{Cu}$ and $\mathrm{Au}-\mathrm{Cu}-\mathrm{Ag}$ alloys of weight compositions (numerical data in wt.\%)Au-(49.6)Cu and $\mathrm{Au}-(15.07) \mathrm{Cu}-(34.82) \mathrm{Ag}$ (in brief, $\mathrm{Au}-(50) \mathrm{Cu}$ and $\mathrm{Au}-(15) \mathrm{Cu}-(35) \mathrm{Ag}$, respectively)were prepared by induction melting. High purity raw materials(Au: 99.999\%, Cu: $99.999 \%$, Ag: 99.999\%) have been used for the production. Using electron probe micro-analysis (EPMA), the chemical compositions of the homogenized samples were measured with an accuracy of $\pm 0.2 \%$.

The samples were homogenized at $700^{\circ} \mathrm{C}$ for 2 hours, under vacuum, to obtain the disorder state, A1 for the binary composition and the solid solution a for the ternary composition, followed by water quenching (the homogenization conditions have been chosen based on the results of ref [16]). Then, the samples were heated from room temperature up to temperatures between 100 and $220^{\circ} \mathrm{C}$, followed by water quenching.

\subsection{Characterization}

\subsubsection{Thermal analyses}

The DSC measurements were carried out under argon with a Setaram DSC 131 (with precision of about $0.4 \mathrm{~mW} / 7 \times 10^{-5}{ }^{\circ} \mathrm{C}$ ). Cylindrical samples of $3 \mathrm{~mm}$ in diameter and 1 $\mathrm{mm}$ long were used for DSC analyzes corresponding to a weight of approximately 100 $\mathrm{mg}$. The dilatometric analyzes were carried out under argon using a DT1000 AdamelL homargy dilatometer connected to a microcomputer with software (DT1000) to analyze the obtained results (with precision of about $0.2 \times 10^{-6} / 0.02^{\circ} \mathrm{C}$ ). A cylindrical samples of $1.5 \mathrm{~mm}$ in diameter and $15 \mathrm{~mm}$ long were used for dilatometric analyzes. The applied thermal cycles consisted of heating from room temperature to $300{ }^{\circ} \mathrm{C}$ for both thermal techniques. For these both techniques heating rate of $10 \mathrm{~K} / \mathrm{min}$ has been used basing on the results of ref [16].

\subsubsection{Morphological analyses}

STM and SEM were carried out on heat treated and quenched samples. The size distribution and particle morphology of nanoparticles were investigated using scanning tunneling microscopy (STM) by means of VT AFM XA instrument, under UHV with exchangeable in-situ tips, and scanning electron microscopy (SEM) by means of FEGSEM-FEl instrument, using secondary electron mode with accelerating voltage of $10 \mathrm{kV}$. 


\subsubsection{Further used techniques}

$X$-ray photon spectroscopy (XPS) experiments were performed using a SPECS Phoibos 100 MCD5 hemispherical electron analyser operating at a constant pass energy, using an x-ray source $\mathrm{Ka} \mathrm{Mg}(1253.6 \mathrm{eV})$ and a flood electron gun to compensate for charge effects on the samples. Low resolution survey spectra were taken using $90 \mathrm{eV}$ of energy pass and $1 \mathrm{eV}$ of step energy, whereas high resolution spectra were taken with $30 \mathrm{eV}$ energy pass and $0.1 \mathrm{eV}$ step energy. The background pressure in the analysis chamber was kept below $5 \times 10^{-9}$ mbar during data acquisition. All spectra were measured at room temperature

$X$-Ray Diffraction with small diffraction angles has been performed using GrazingIncident X-ray diffraction with an angle omega of 5 Degrees which, analyze up to 1 micron of depth. To achieve this surface measurement, narrow incident slits were used (Primary Divergence $1 / 8^{\circ}$ and Anti-scatter $14^{\circ}$ ) together with Parallel Plate collimator of $0.18^{\circ}$ and Secondary Anti-scatter slit of $8 \mathrm{~mm}$. Scan was performed in 2Theta range between $20-60^{\circ}$ with a step of $0.025^{\circ}$ and counting time of $8 \mathrm{~s}$ per point.

Normal X-Ray Diffraction has been performed using Panalytical XPERT-PRO diffractometer which use copper $\mathrm{K}_{\alpha}$ radiation $\left(1.5418 \mathrm{~A}^{\circ}\right)$.

\section{Results and discussion}

\subsection{Results of previous experiments on AuCu equiatomic system}

In previous study of Hamana et al [16], a new reaction have been detected at low temperature using DSC in the equiatomic $\mathrm{Au}-\mathrm{Cu}$ system, where they have used several heating velocities for the same homogenization temperature to check if this phase appear independently to the heating rate and they found that more the velocity gets higher more the peak gets sharper but it exists anyway. On the other hand they have studied the effect of the temperature of homogenization on this peak and they found that arriving to $750^{\circ} \mathrm{C}$ and more, there is diffusion of this peak with the one corresponding to the ordering reaction, and bellow $750^{\circ} \mathrm{C}$ there is separation between the two peaks.

Since this kind of phase transitions affects crucially the physical properties of the material especially the mechanical part [17-20], and basing on these previous results, our study is concerned with using another compositions of 12-carat gold alloys instead of 18 carat (Au-25\%mass $\mathrm{Cu}$ ) used by Hamana et al [16] and using different experimental conditions and characterization techniques. 


\subsection{DSC and Dilatometric studies}

According to the used thermal treatment, the starting state for the DSC and the dilatometric tests is the disorder for both compositions i.e. A1 for the binary and the solid solution $\alpha$ for the ternary composition (As confirmed with the XRD spectra in figure 1). The corresponding curves have been focalized at the area bellow $300^{\circ} \mathrm{C}$, the region where the anomaly have been found in ref. [16].

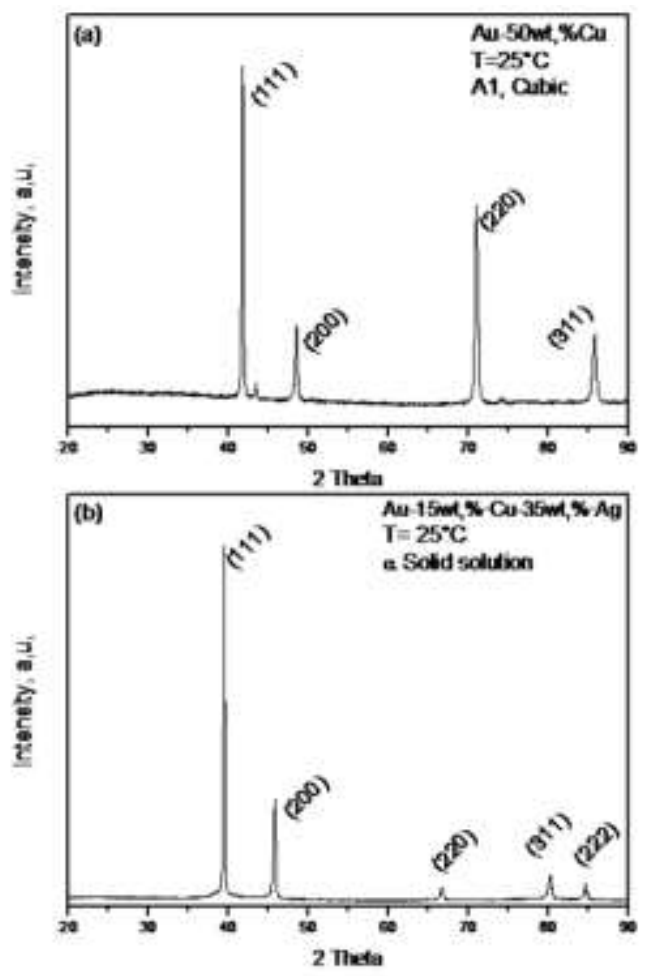

Figure 1. X-ray diffraction spectra in the initial state after the homogenization and water quenching (before heating up) of the $\mathrm{Au}-(50) \mathrm{Cu}(\mathrm{a})$ and $\mathrm{Au}-(15) \mathrm{Cu}-(35) \mathrm{Ag}(\mathrm{b})$.

The obtained DSC heating curves are presented in figure 2. On the basis of the binary and ternary phase diagrams $[8,12,13]$ and on the starting state for the thermal analyses which is the disorder in both compositions, the analyze of the first heating curve which corresponds to the binary composition $\mathrm{Au}-(50) \mathrm{Cu}$ (fig. 2 (a)) shows two discerned exothermic peaks $\mathbf{P 1}$ and $\mathbf{P 2}$ with two maximums situated at $165{ }^{\circ} \mathrm{C}$ and $208{ }^{\circ} \mathrm{C}$. The appearance of the first peak (P1) confirms that the reaction discussed by Hamana et al [16] at low temperature is also present in the binary 12-carat alloy. The second peak (P2) corresponds to the ordering reaction presented in $\mathrm{A} 1-\mathrm{AuCu}_{3}$ phase transition.

Concerning the ternary composition, $\mathrm{Au}-(15) \mathrm{Cu}-(35) \mathrm{Ag}$, the DSC heating curve (fig. 2(b)) shows the presence of three exothermic peaks $(\mathbf{P 1})$ located at $120^{\circ} \mathrm{C}$ which is likely 
to be a sign of the pre-ordering reaction at low temperature in the ternary composition. As it is shown in ref. [21], the silver presence in Au-Cu system leads to the acceleration of the ordering reaction, this pre-ordering reaction should also be accelerated as figure 2 (b) shows. The second and the third peaks in the ternary composition (P2) and (P3),located at 210 and $266^{\circ} \mathrm{C}$ respectively, correspond to the phase separation embodied in the fact of the precipitation of $\alpha_{1}$ reach in silver then $\alpha_{2}$ reach in copper phases[12,13].
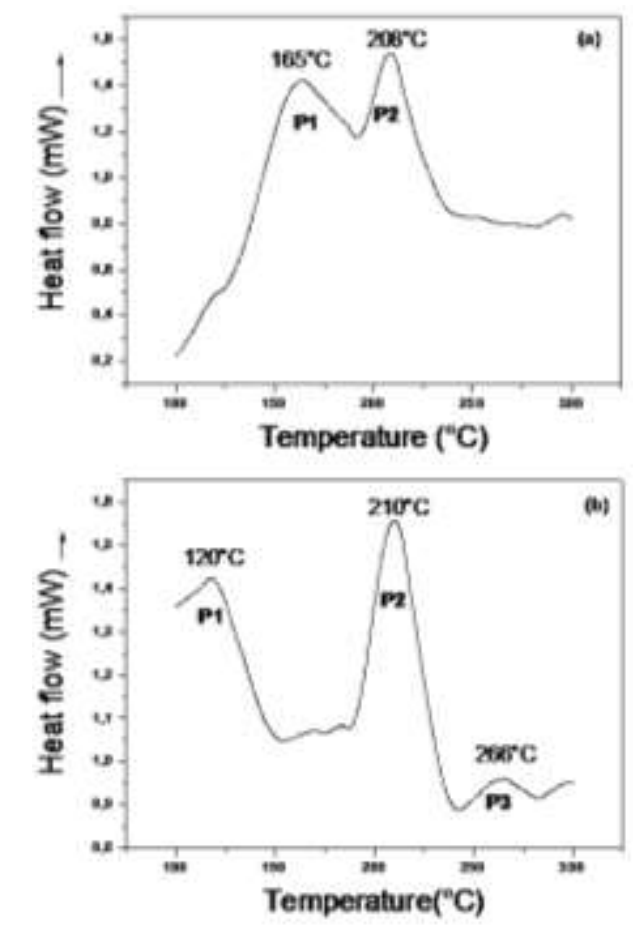

Figure 2.DSC curves of $\mathrm{Au}-(50) \mathrm{Cu}(\mathrm{a})$ and $\mathrm{Au}-(15) \mathrm{Cu}-(35) \mathrm{Ag}(\mathrm{b})$ homogenized $2 \mathrm{~h}$ at $700{ }^{\circ} \mathrm{C}$, and water quenched.

The dilatometric study has been done to confirm the results already observed by the DSC with the same experimental conditions. The obtained curves are presented in figure 3.The derivative curve of the heating segment, corresponding to the binary $\mathrm{Au}(50)-\mathrm{Cu}$ sample (fig. 3(a)), shows a large contraction situated between 120 and $280^{\circ} \mathrm{C}$ which results from an overlap of two peaks corresponding to the first reaction at low temperature (pre-ordering) and the formation of the ordered phase $\mathrm{AuCu}_{3}$ represented in (P1) and (P2).

The derivative dilatometric heating curve corresponding to the $\mathrm{Au}-(15) \mathrm{Cu}-(35) \mathrm{Ag}$ ternary composition (fig. 3(b)) exhibits a large contraction situated between 50 and $269^{\circ} \mathrm{C}$ represents an overlap of two peaksP1 and P2 and a second clear peak P3between 269 and $300^{\circ} \mathrm{C}$ with a minimum situated at $288^{\circ} \mathrm{C}$. P1 corresponds to the pre-ordering 
reaction at low temperature. $\mathbf{P} 2$ and $\mathbf{P} 3$ correspond to the precipitation of $\alpha_{1}$ reach in silver and $\alpha_{2}$ reach in copper phases respectively $[12,13]$.

The above results indicate that the DSC and the dilatometric curves are in a good agreement. To investigate the origin of the unknown first peak which appears at low temperature, further techniques are required.
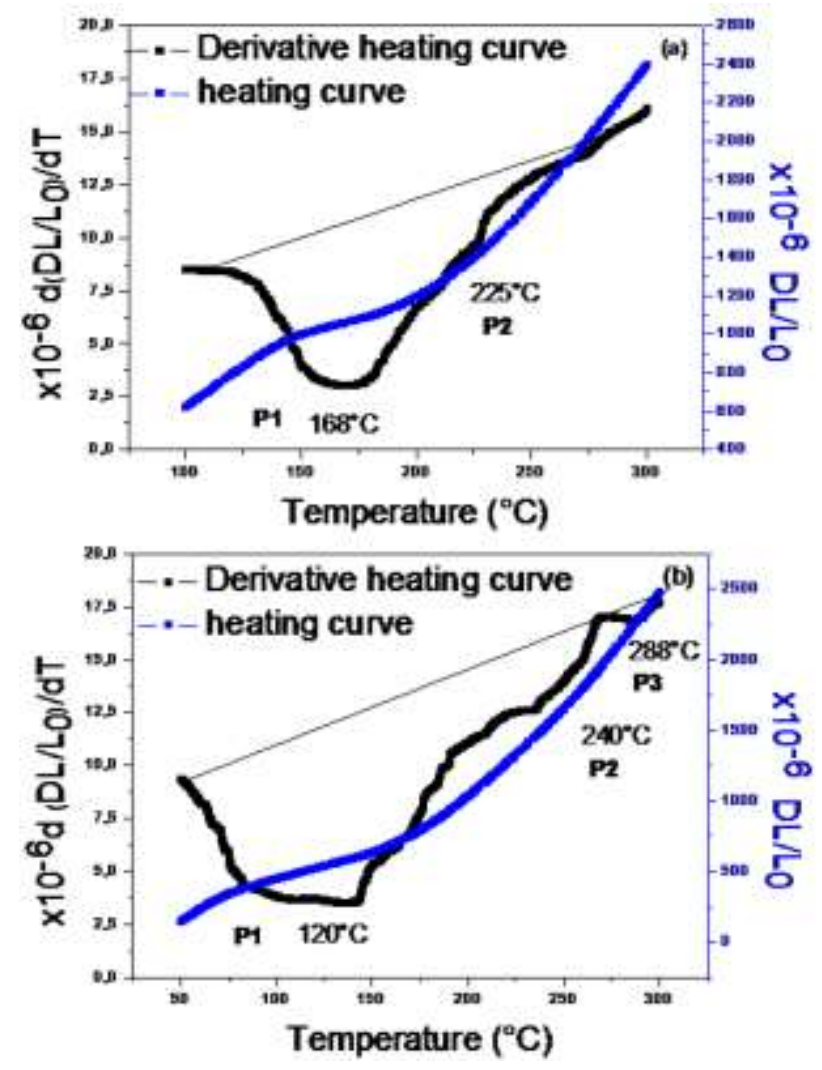

Figure 3. Dilatometric curves and derivative heating curves of $\mathrm{Au}-(50) \mathrm{Cu}(\mathrm{a})$ and $\mathrm{Au}-$ (15) Cu-(35) Ag (b) samples homogenized $2 \mathrm{~h}$ at $700^{\circ} \mathrm{C}$, and water quenched.

\subsection{Morphological study (SEM and STM)}

As the imaging study is important for the phase transitions, we used two techniques SEM and STM. The SEM images have been taken on two serious of samples, from the disorder and from the order. Knowing that at $700^{\circ} \mathrm{C}$ we did not notice any anomaly or special appearance neither in SEM nor in STM images for the both compositions.

\subsubsection{SEM study from the disordered state}

The used samples in this part were in the disordered phase $\mathrm{A} 1$ for the binary and the solid solution a for the ternary compositions, obtained after annealing for two hours at 
$700^{\circ} \mathrm{C}$ followed by water quenching. As first step, the annealed samples have been heated from room temperature up to $160^{\circ} \mathrm{C}$ with different holding times $(0,10$, and $20 \mathrm{~min}$ )for both compositions. The second step was concerned with SEM imaging of samples heating from room temperature up to $140,180,200$, and $220^{\circ} \mathrm{C}$ for the binary composition and up to $100,120,140,180^{\circ} \mathrm{C}$ for the ternary composition as clarified in Scheme 1:

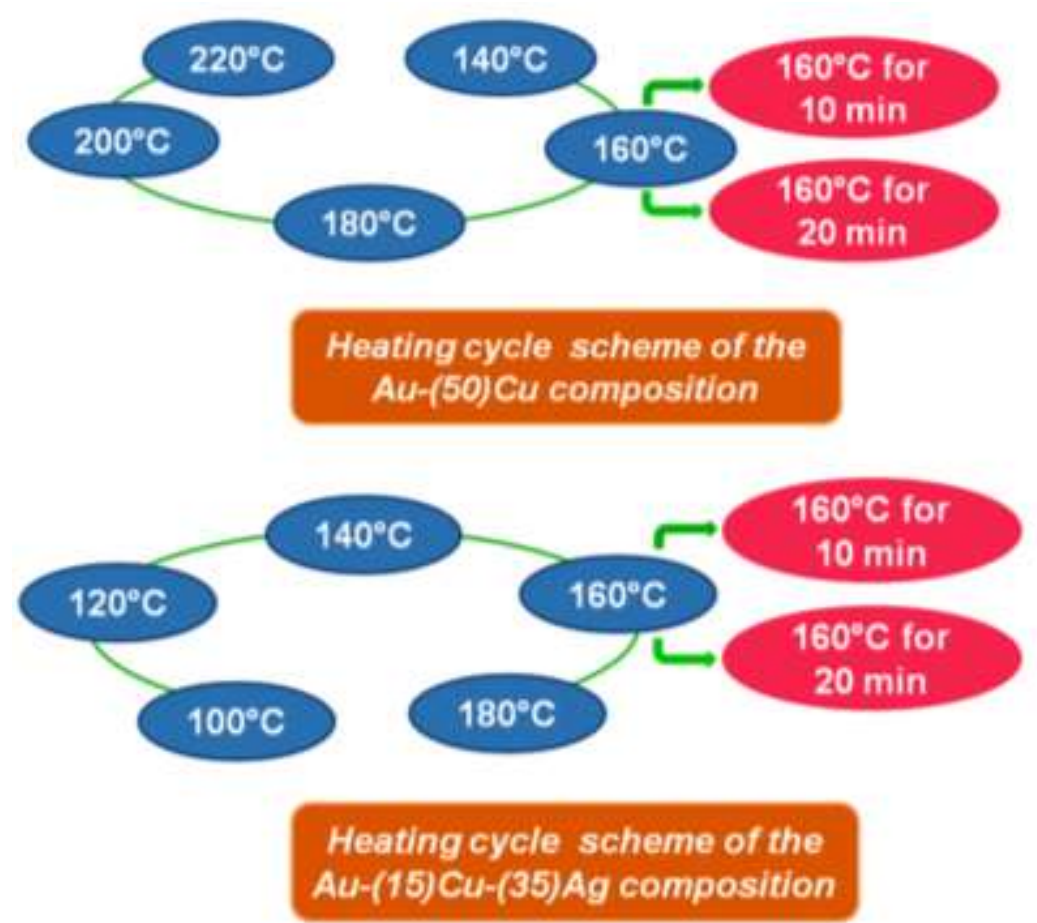

Scheme 1.Heating cycle schemes of the SEM study from the disordered state.

\subsubsection{The binary composition $\mathrm{Au}-(50) \mathrm{Cu}$}

Figure 4 presents SEM images of the binary composition taken at $160^{\circ} \mathrm{C}$. The simple heating up to $160^{\circ} \mathrm{C}$ without holding (fig. $4(a, b)$ ) leads to the appearance of cubic precipitates scattered on the sample surface. The holding at $160^{\circ} \mathrm{C}$ for $20 \mathrm{~min}(\mathrm{Fig} .4(\mathrm{c}, \mathrm{d})$ ) leads to remarkable increase in precipitates density with dendrite shape.

The noticeable effect of the pre-ordering reaction on sample surface aspect proved by figure 4 after heating up to $160^{\circ} \mathrm{C}$, and to follow the formation kinetic of these precipitates, heating up to lower and upper temperatures than $160^{\circ} \mathrm{C}$ have been carried out. 
Figure 5 presents the corresponding SEM images. For upper temperatures, Figure $5(a, b)$ correspond to the heating up to $180^{\circ} \mathrm{C}$. The precipitates are homogeneously scattered on the whole surface with dendrites shape instead of cubes at $160^{\circ} \mathrm{C}$ (fig.4(a,b)). Figure $5(\mathrm{c}, \mathrm{d})$ correspond to the heating up to $200^{\circ} \mathrm{C}$. The precipitates are much bigger by comparison to figure.5(a,b). Figure 5(e) corresponds to the heating up to $220^{\circ} \mathrm{C}$. It shows the total absence of any precipitates on the whole surface. For temperature lower than $160^{\circ} \mathrm{C}$, SEM image after heating up to $140^{\circ} \mathrm{C}$ presented in figure $5(f)$, there is no precipitates.

The SEM images for the binary composition prove that the precipitation on the sample surface starts at $160^{\circ} \mathrm{C}$, by the appearance of scattered cubes on the whole sample surface. By increasing the holding time, the precipitates get more dense and take a dendrites shape (fig.4). The cubes that present the onset of the precipitates at $160^{\circ} \mathrm{C}$, become dendrites at 180 and $200^{\circ} \mathrm{C}$ then the precipitates disappear beyond $200^{\circ} \mathrm{C}$ (fig.5).
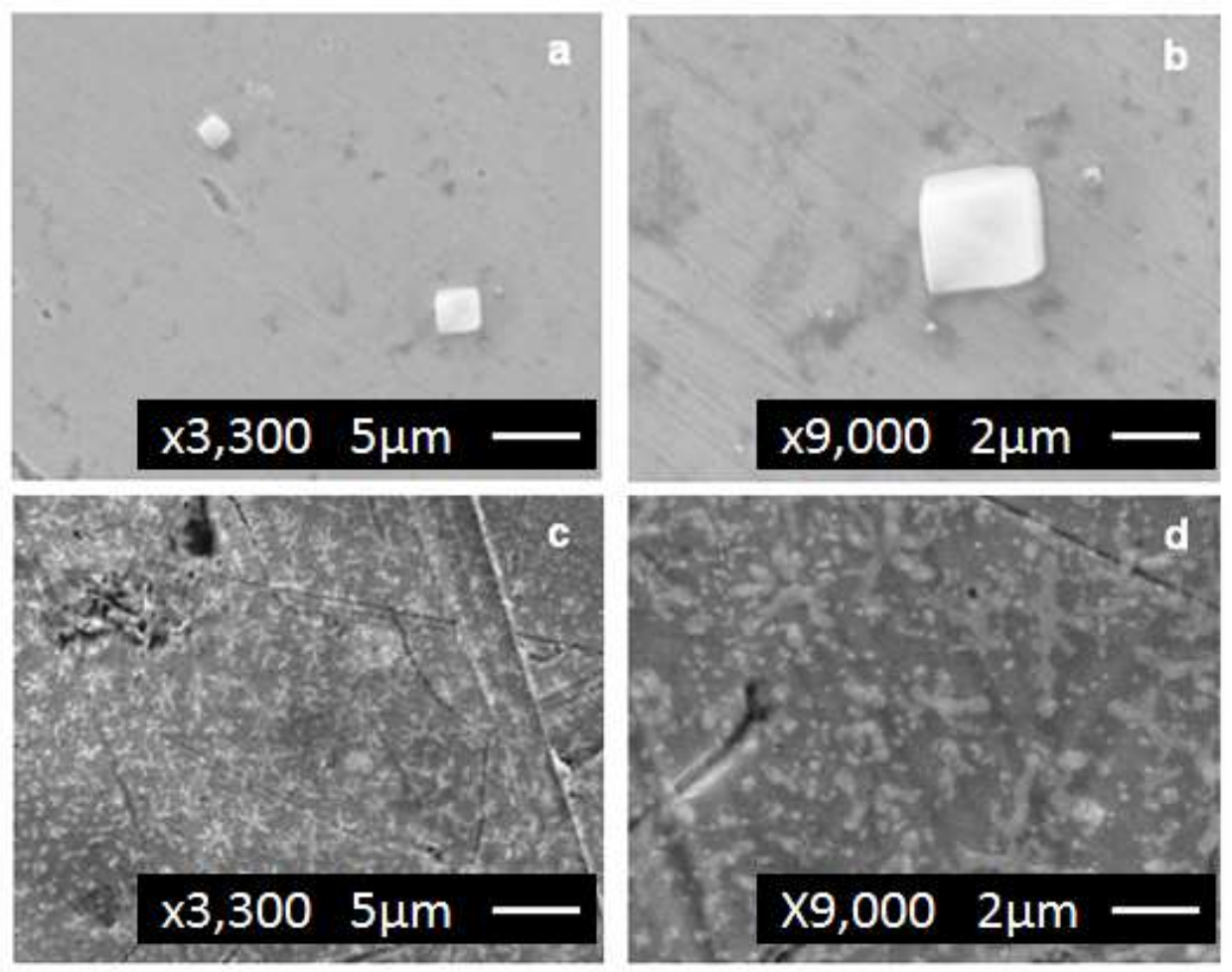

Figure 4.SEM surface morphology of $\mathrm{Au}-(50) \mathrm{Cu}$ sample, heated from the disorder up to $160^{\circ} \mathrm{C}$ without holding then water quenched $(a, b)$, with holding $20 \mathrm{~min}$ at $160^{\circ} \mathrm{C}$ followed by water quenching $(c, d)$. 

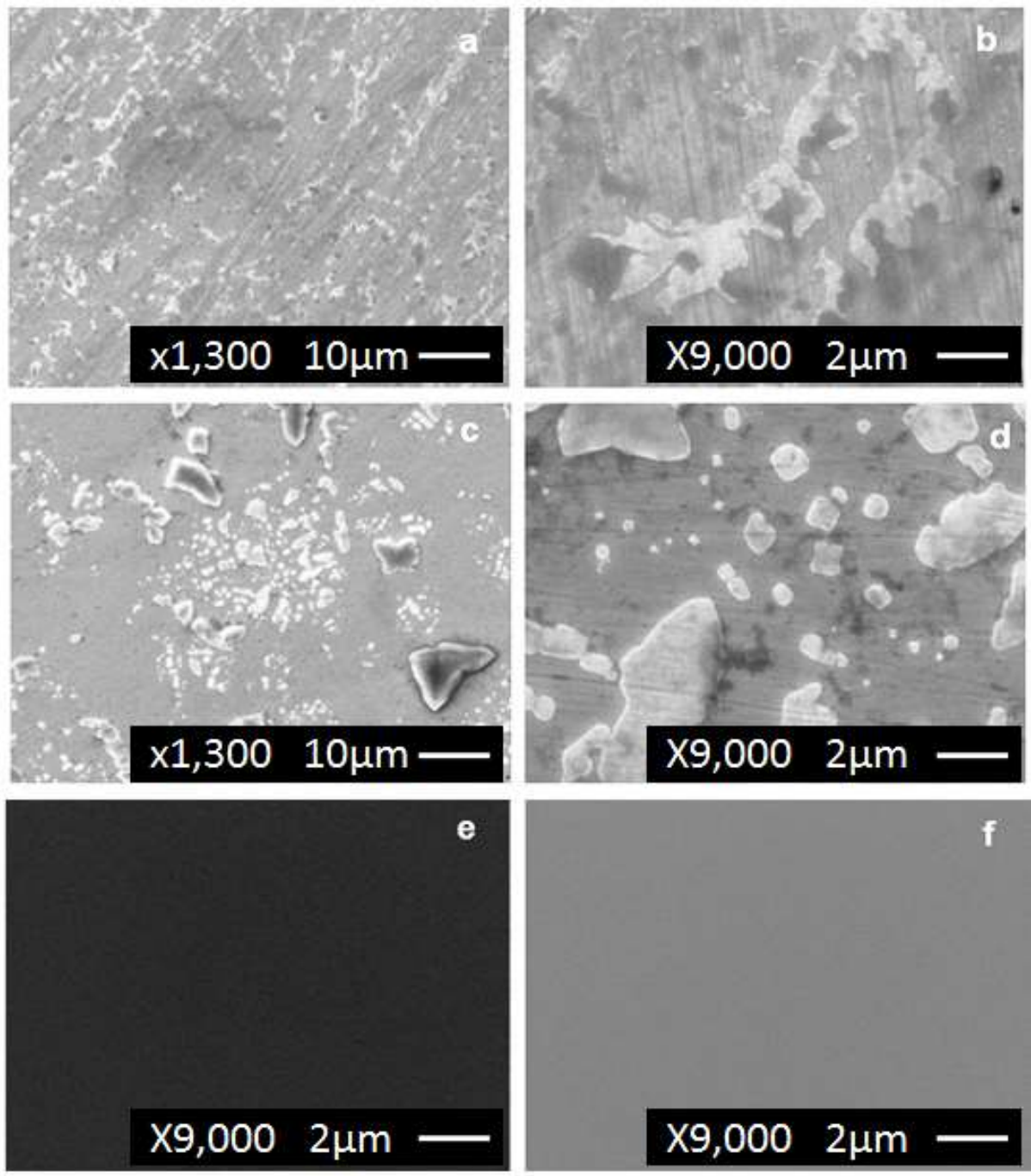

Figure 5. SEM surface morphology of $\mathrm{Au}-(50) \mathrm{Cu}$ sample heated from the disorder up to $180^{\circ} \mathrm{C}(\mathrm{a}, \mathrm{b})$, to $200^{\circ} \mathrm{C}(\mathrm{c}, \mathrm{d})$, to $220^{\circ} \mathrm{C}(\mathrm{e})$ and to $140^{\circ} \mathrm{C}(\mathrm{f})$, without holding. Where in the (a) image the whole sample surface were covered homogeneously with the dendrites. For the (c) image only some few spots on the surface presented the presence of the precipitates.

\subsubsection{The ternary composition Au-(15)Cu-(35)Ag}

Figure 6 presents SEM images of the ternary composition taken at $160^{\circ} \mathrm{C}$. Figure $6(a, b)$ correspond to simple heating up to $160^{\circ} \mathrm{C}$, and it exhibits large precipitates with dendrite shape. Figure $6(\mathrm{c}, \mathrm{d}, \mathrm{e})$ are taken after heating up with holding for $10 \mathrm{~min}$ at $160^{\circ} \mathrm{C}$, and it exhibits that the dendrites get thinner and longer with a filamentary extension by comparison to the case without holding at $160^{\circ} \mathrm{C}$ (fig.6 (a, b)) after holding for $20 \mathrm{~min}$ at $160^{\circ} \mathrm{C}$ the precipitates disappear completely from the whole surface (fig.6(f)). 
After the noticeable effect of the pre-ordering reaction on sample surface aspect proved by figure 6 after heating up to $160^{\circ} \mathrm{C}$, and to follow the formation kinetic of these precipitates for the ternary composition, heating up to lower and upper temperatures than $160^{\circ} \mathrm{C}$ have been carried out. Figure 7 presents the corresponding SEM images.

For temperature upper than $160^{\circ} \mathrm{C}$, Figure 7 (a) corresponds to the heating up to $180^{\circ} \mathrm{C}$, the image shows the total disappearance of the precipitates.

For lower temperatures, SEM image after heating up to $140^{\circ} \mathrm{C}$ presented in figure 7 (b), shows the presence of scattered cubes on the sample surface as precipitates. More lower, $120^{\circ} \mathrm{C}$ (fig.7(c)) also cubes scattered on samples surface. However, going more down to $100^{\circ} \mathrm{C}$ (fig. $7(\mathrm{~d})$ ), there is no impress of precipitates is noticeable.

The SEM images for the ternary composition prove that the precipitation on the sample surface starts at $120^{\circ} \mathrm{C}$, by the appearance of scattered cubes on the whole sample surface. The cubes persist on the surface with the increase of the temperature where they become large dendrites from 140 to $160^{\circ} \mathrm{C}$. By increasing the holding time at $160^{\circ} \mathrm{C}$ these dendrites get longer and thinner in order to disappear completely after $20 \mathrm{~min}$ of holding at $160^{\circ} \mathrm{C}$.

The SEM images and the kinetic study are in very good agreement and explain very well the positions of the first peaks that correspond to the pre-ordering reaction in the DSC and the dilatometric studies as shown in figure. 2 and 3 for both compositions. Where, the thermal study using DSC and dilatometry shows that the pre-ordering reaction in the binary composition have a maximum at $160^{\circ} \mathrm{C}$ which is the same temperature of the precipitates onset. For the ternary composition, $120^{\circ} \mathrm{C}$ is the preordering reaction peak maximum in DSC and dilatometry and as well it presents the onset temperature of the precipitates. The SEM kinetic study, prove the direct relationship of these peaks to the precipitations on sample surfaces. 

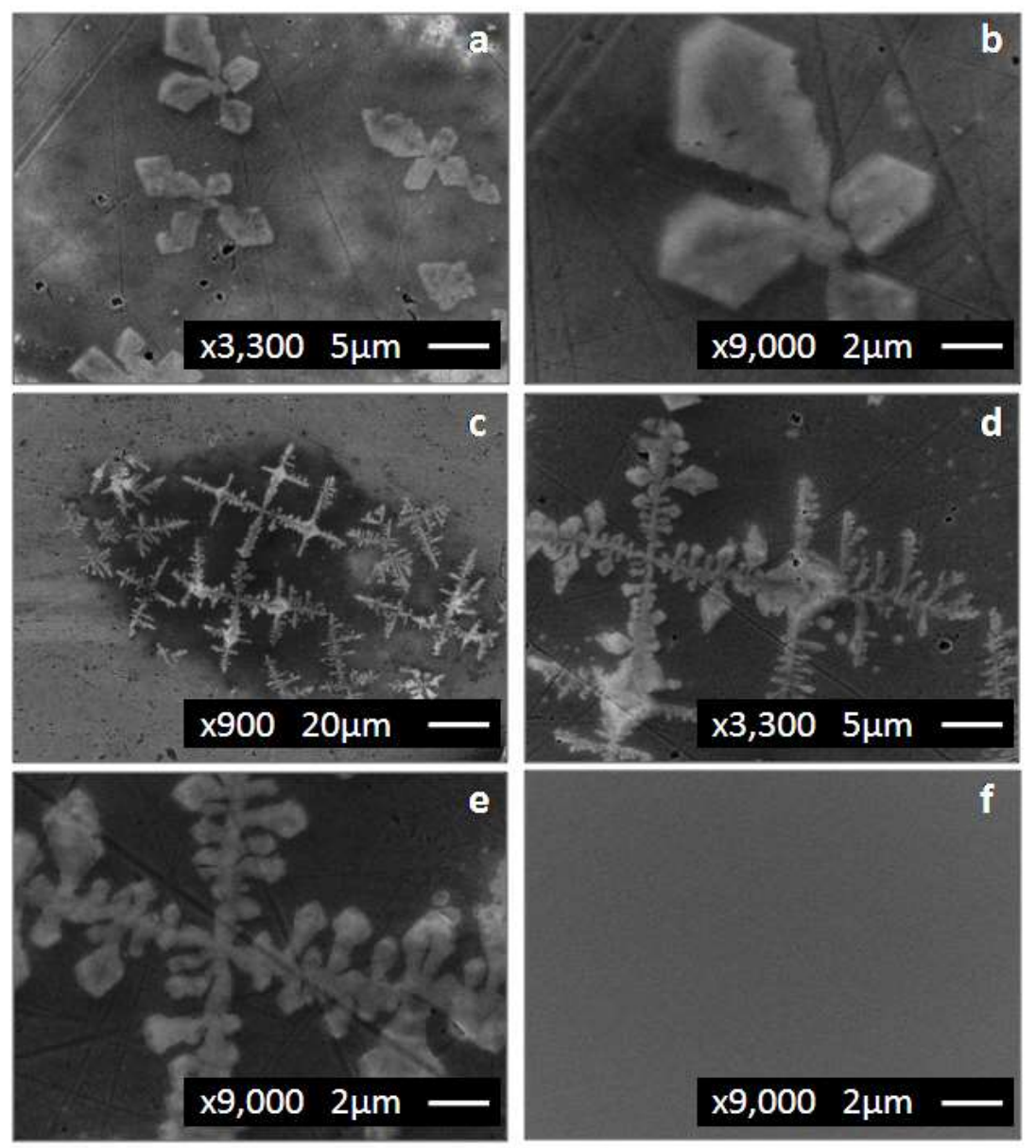

Figure 6.SEM surface morphology of $\mathrm{Au}-(15) \mathrm{Cu}$-(35)Agcomposition, heated from the disorder up to $160^{\circ} \mathrm{C}$ water quenched without holding $(a, b)$, with holding $10 \mathrm{~min}$ at $160^{\circ} \mathrm{C}$ $(\mathrm{c}, \mathrm{d}, \mathrm{e})$ and with holding at $160^{\circ} \mathrm{C}$ for $20 \mathrm{~min}(\mathrm{f})$. 

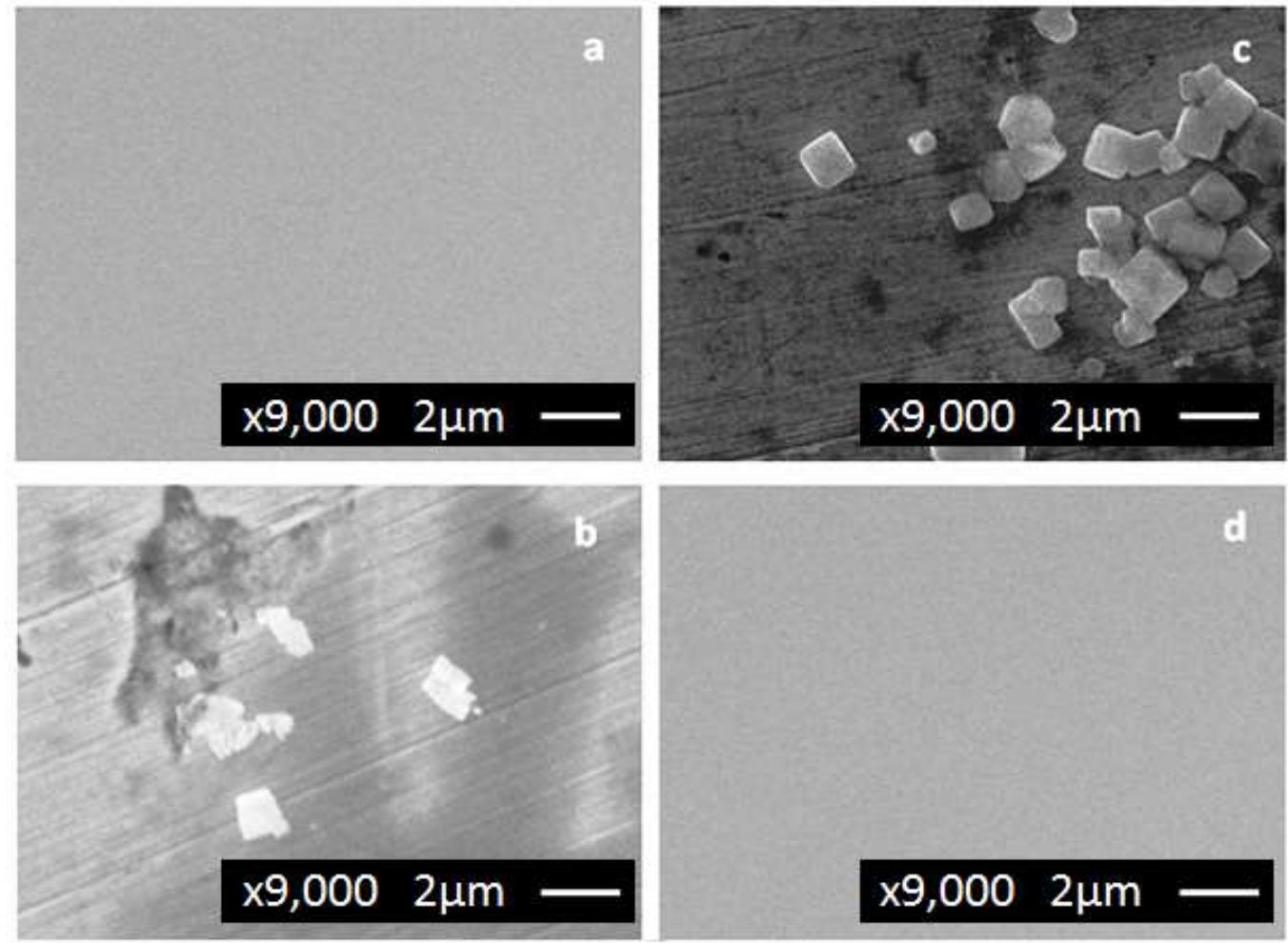

Figure 7. SEM surface morphology of $\mathrm{Au}-(15) \mathrm{Cu}-(35) \mathrm{Ag}$ sample, heated without holding from the disorder up to $180^{\circ} \mathrm{C}(\mathrm{a}), 140^{\circ} \mathrm{C}(\mathrm{b}), 120^{\circ} \mathrm{C}$ (c) and to $100^{\circ} \mathrm{C}(\mathrm{d})$.

\subsubsection{SEM study from the ordered state}

The used samples in this part were in the ordered state i.e. $\mathrm{AuCu}_{3}$ for the binary composition and $\alpha_{1}+\alpha_{2}$ for the ternary composition after slow cooling down from $700^{\circ} \mathrm{C}$ to room temperature. Figure 8 shows the corresponding SEM images. In both compositions there is existance of dendrites where the ternary composition shows dense presences of them.

Moreover, figure 8 demonstrates that the anomaly at low temperature is present upon heating as upon cooling for both binary and ternary compositions of 12-carat gold alloy. These precipitates are denser for the ternary alloy comparing to the binary composition. 

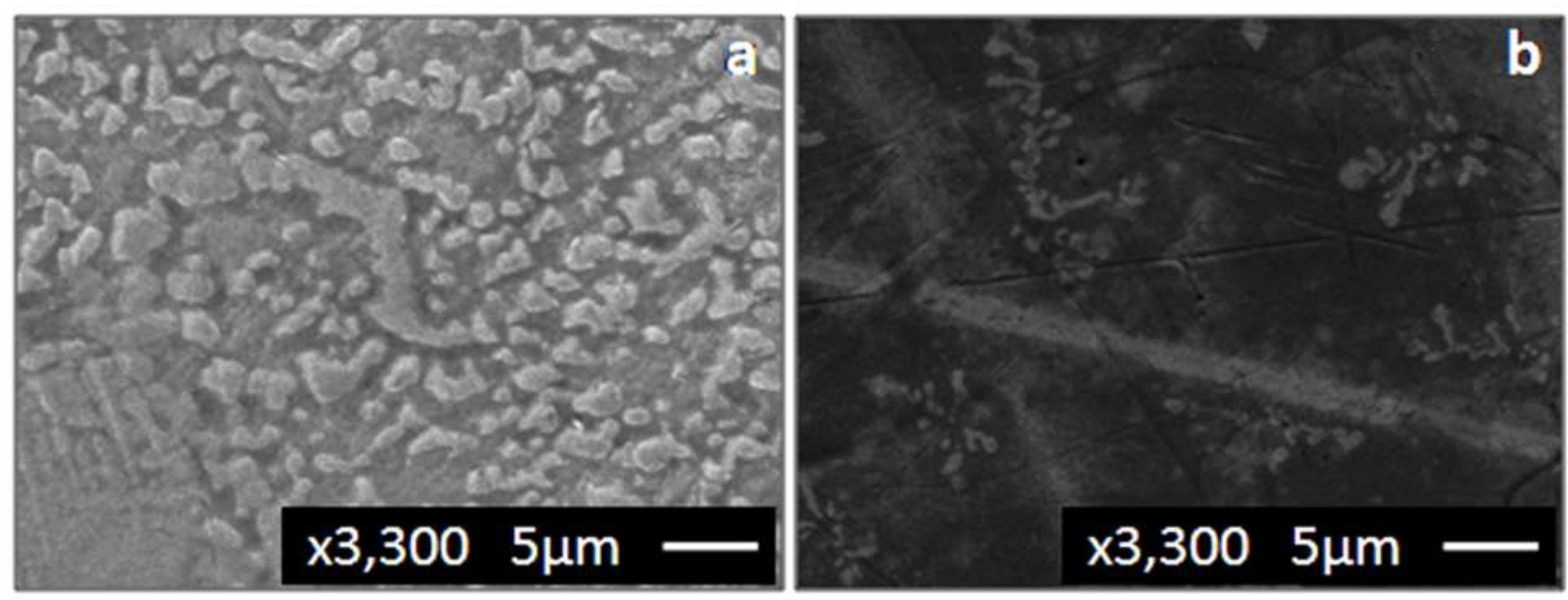

Figure 8. SEM surface morphology of $\mathrm{Au}-(50) \mathrm{Cu}(\mathrm{a})$ and $\mathrm{Au}-(15) \mathrm{Cu}-(35) \mathrm{Ag}$ (b) samples after cooling down from $700^{\circ} \mathrm{C}$ to room temperature using velocity of $1 \mathrm{~K} / \mathrm{min}$.

\subsubsection{STM study}

For more details STM images have been taken for both used compositions. Where, we have chosen $160^{\circ} \mathrm{C}$ as heating up temperature for both alloys because it represents a common temperature where there are precipitations for both alloys. The SEM images taken at $700^{\circ} \mathrm{C}$, which are not presented in this paper, show the total absence of any special physical aspect in the surface. However, the things go differently after heating up to $160^{\circ} \mathrm{C}$.

Figure 9 shows the 2D micrograph and the typical line scans of both studied compositions. Both compositions show a homogeneous distribution of nanoparticles. These nanoparticles are not strongly attached on the sample surface. Where, the scan for several times of the same area exhibits a huge difference in the particles size and shape. 

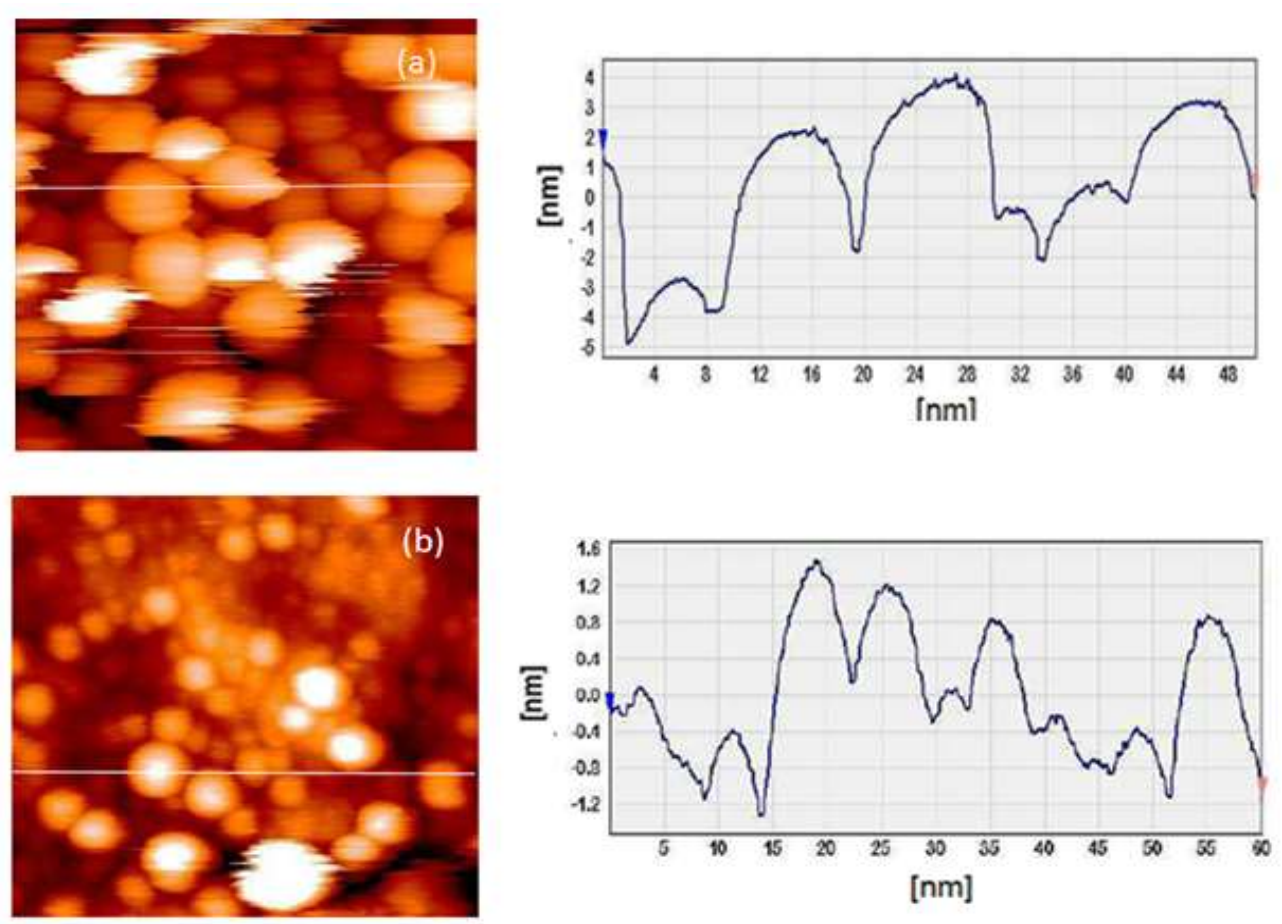

Figure 9. Two dimensions STM micrograph (a,c) and a typical line scan (b,d) of spherical nanoparticles appeared on $\mathrm{Au}-(50) \mathrm{Cu}$ sample surfaces (a) and Au-(15)Cu-(35)Ag (b) homogenized and heated from room temperature up to $\left(160^{\circ} \mathrm{C}\right)$, followed by water quenching.

\subsection{Further techniques}

XPS and small angles X-ray diffraction data have been carried out on heated samples up to $160^{\circ} \mathrm{C}$ only for the ternary composition (fig 10 and 11) in order to determine the nature of the precipitates that appear at low temperature on the surface of gold alloys. Where it is more likely to be a new phase with new properties that precedes the ordering phase transition as pre-ordering reaction. These last techniques have shown the copper oxide as the only new and strange thing that can be detected on the sample surfaces. The energetic positions of the $\mathrm{Cu} 2 \mathrm{p} 3 / 2$ and the $\mathrm{O} 1 \mathrm{~s}$ correspond to the copper oxide $\mathrm{CuO}$. The extra peaks on the small angle X-ray diffraction pattern (fig 12) correspond to the copper oxide CuO. Where, the window of the XPS is a rectangle of " $3.5 \times 1 \mathrm{~mm}^{2}$ " which presents an incidence beam size much bigger than the size of the precipitates in these 12-carat compositions, the small angle X-ray diffraction although it is concerned only with the surface but it still has small penetration in the very superficial part " almost 1 micron of depth". Both techniques confirm the copper oxide. 


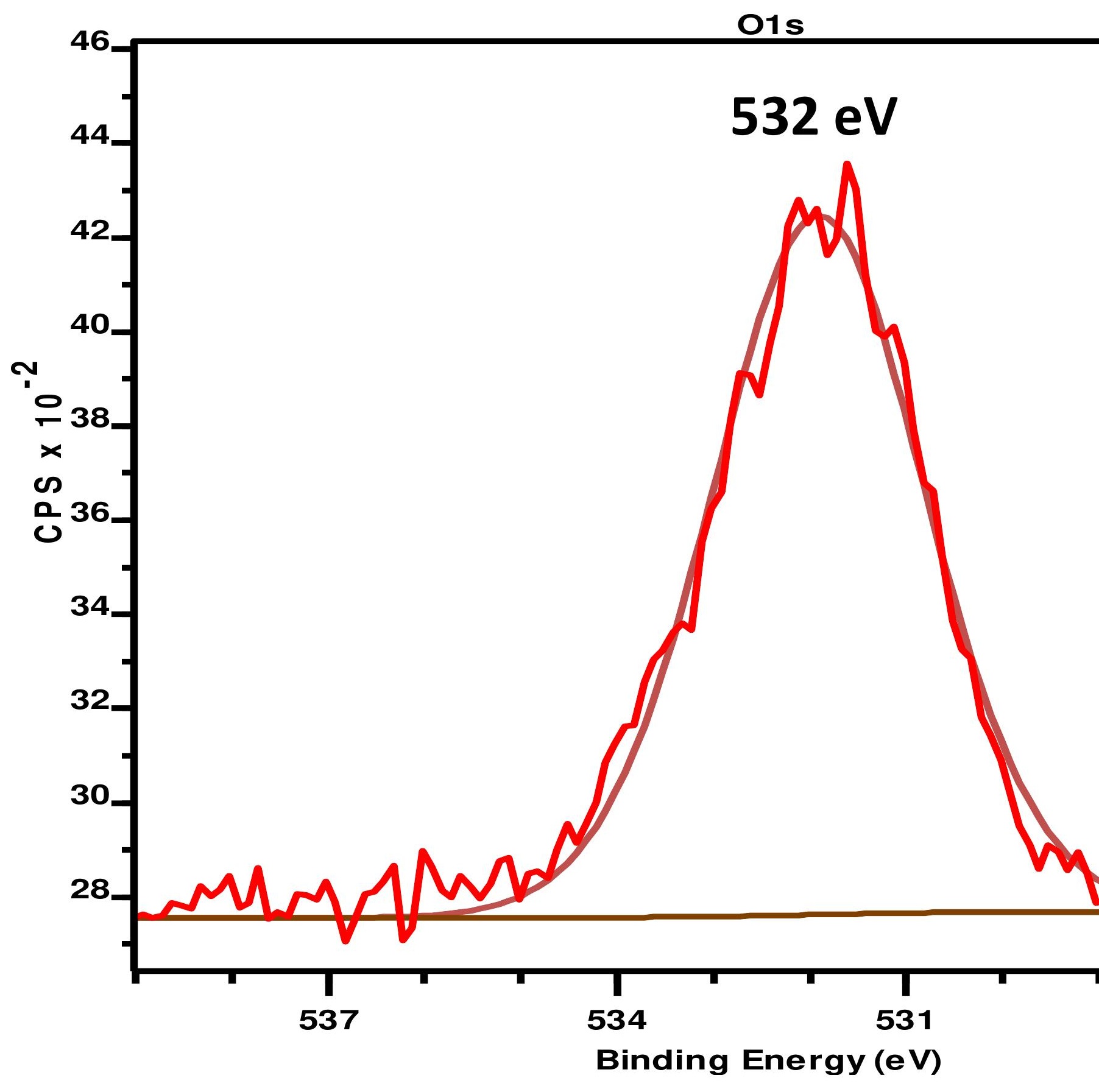




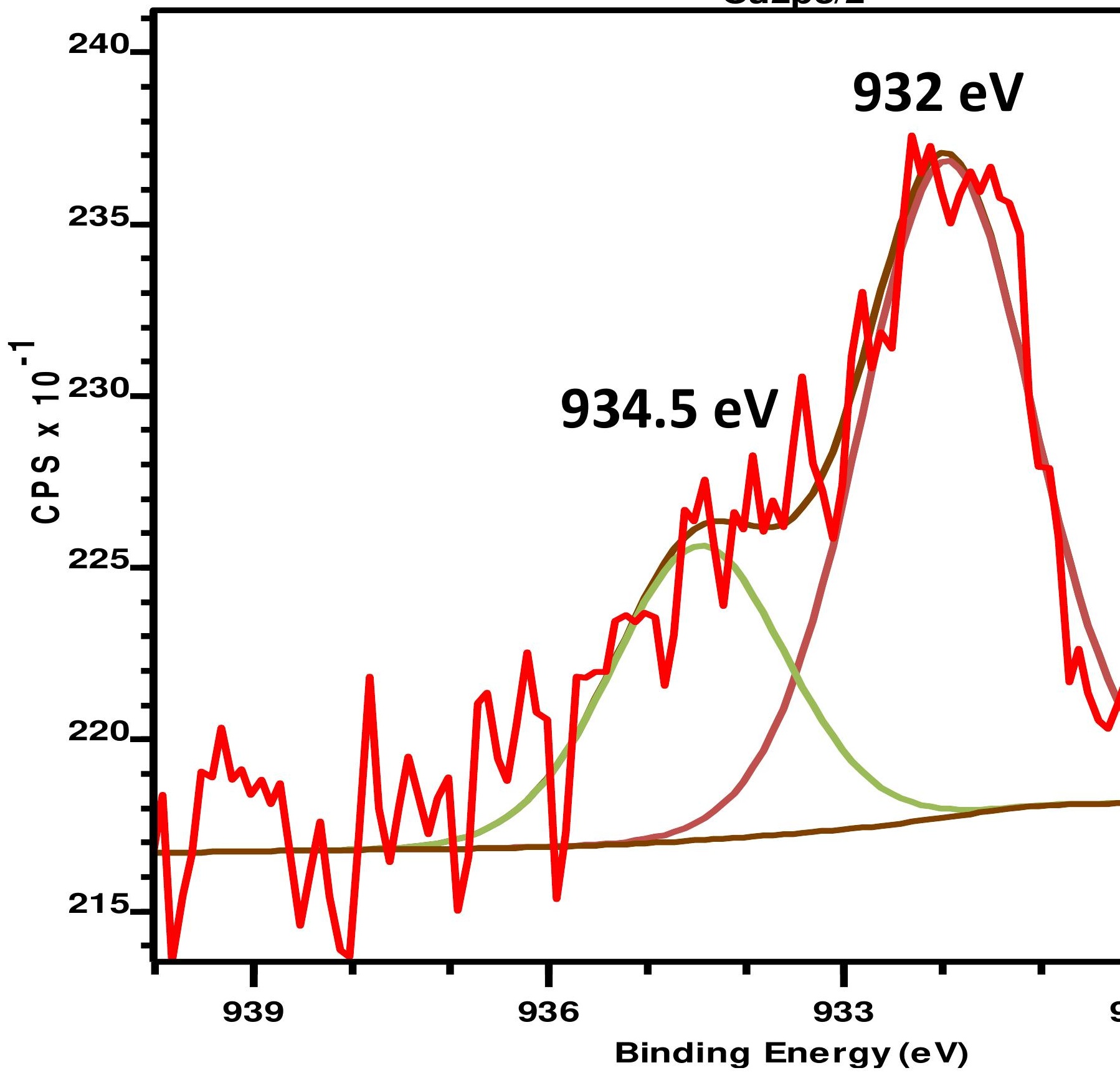

Figure 10. XPS spectra of $\mathrm{Cu} 2 p$ and $\mathrm{O} 1 \mathrm{~s}$ of $\mathrm{Au}-(15) \mathrm{Cu}-(35) \mathrm{Ag}$ composition after heating up to $160^{\circ} \mathrm{C}$. 


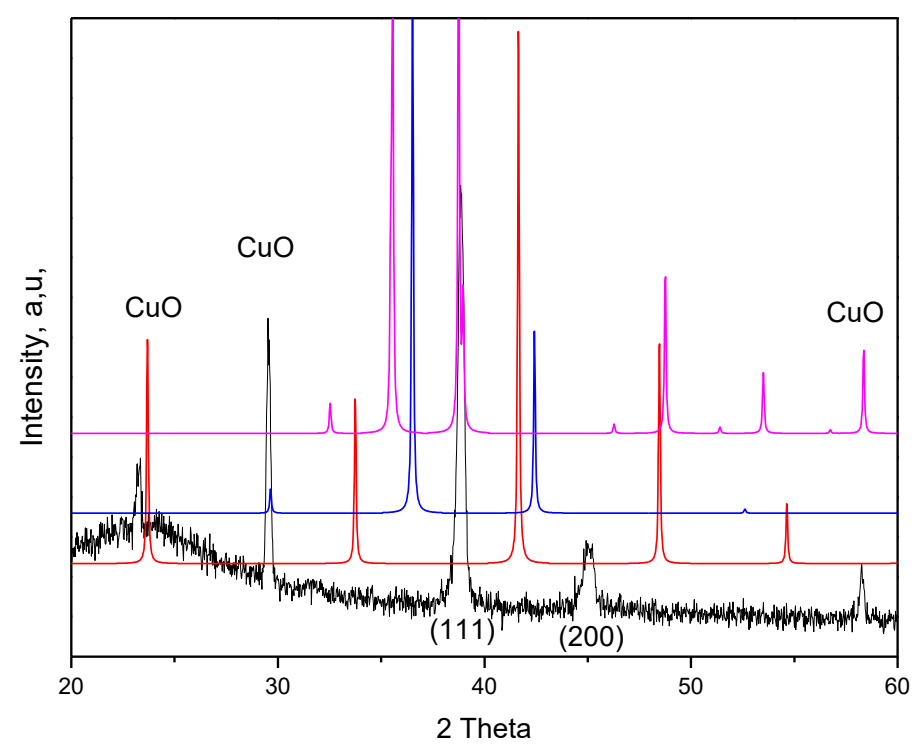

Figure 11. Small angles X-ray diffraction spectra of $\mathrm{Au}-(15) \mathrm{Cu}-(35) \mathrm{Ag}$ composition after heating up to $160^{\circ} \mathrm{C}$.

\section{Conclusion}

A new anomaly at low temperature has been investigated in ref [16] for 18-carat binary composition. This paper has proven the appearance of such new reaction in binary and ternary 12-carat gold alloys. The new phase transition at low temperature has been assessed as pre-ordering reaction using thermal analyzes DSC and dilatometery. SEM technique has a big virtue to attribute this unknown phase transition to the precipitation of some new phase on sample surface with dendrite shapes from 160 to $200^{\circ} \mathrm{C}$ for the binary composition and from 120 to $160^{\circ} \mathrm{C}$ for the ternary composition. STM technique showed that these precipitates are accompanied with nanoparticles that are neither stable nor strongly attached on sample surfaces.

The obtained results provide an important background for the study of the the fundamental mechanisms underlying phase transitions from thermodynamic metastable phase to thermodynamic stable one.

According to the dendrite size in the used 12-carat compositions and to well investigate this new metastable phase in order to determine the exact composition and 
structure, very precise techniques are needed and recommended to be used as in-situ temperature TEM or more rigorously atom probe technique.

\section{Acknowledgments:}

Financial support from the AlgerianMinistry of Higher Education and Scientific Research (PNE scholarship),Spanish Ministerio de Economía y Competitividad (MAT2016-78155C2-1-R and FPI grant BES-2011-046948 to MSM.A.) and Gobierno del Principado deAsturias (GRUPIN14-060).are acknowledged.

\section{References}

[1] Chen G, Ni X and Nsongo, T 2004 Lattice parameter dependence on long-range ordered degree during order-disorder transformation Intermetallics. 12 733-9.

[2] Tanaka Y, Udoh K I, Hisatsune K and Yasuda K 1994 Spinodal ordering in the equiatomicAuCu alloy Philos. Mag. A. 69 925-38.

[3] Bhatia M L, and Cahn R W 2005 Lattice parameter and volume changes on disordering Intermetallics. 13 474-83.

[4] Papageorgiou D G, Lekka C E and Evangelakis G A 2003 Molecular Dynamics study of $\mathrm{Cu}$ and $\mathrm{Au} 2 \mathrm{D}$ adlayers on the $\mathrm{Cu} 3 \mathrm{Au}\left(\begin{array}{lll}1 & 1 & 0\end{array}\right)$ surface Appl. Surf. Sci.219 64-73.

[5] Shedbalkar U, Singh R, Wadhwani S, Gaidhani S and Chopade B A 2014 Microbial synthesis of gold nanoparticles: current status and future prospects Adv. Colloid Interface Sci.209 40-8.

[6] Šíma V 2002 Two models of solid-solid transformation kinetics in the CuAu intermetallic compound Mater.Sci.Eng., A. 32462-7.

[7] Sprušil B and Chalupa B 2002 Checking the model for dynamic disordering in CuAuMater. Sci. Eng., A. 324 58-61.

[8] Fedorov P P and Volkov S N 2016 Au-Cu Phase Diagram Russ. J. Inorg. Chem61772-5.

[9] Bonneaux J and Guymont M 1999 Study of the order-disorder transition series in AuCu by in-situ temperature electron microscopy Intermetallics. 7 797-805.

[10] Okamoto H, Chakrabarti D J, Laughlin D E and Massalski T B 1987 Alloy Phase Diagrams8 454.

[11] Anraku T, Sakaihara I, Hoshikawa T and Taniwaki M 2009 Phase transitions and thermal expansion behavior in AuCu alloy J.Materials transactions.50683-8. 
[12] Prince A, Raynor G V and Evans D S 1990 Phase diagrams of ternary gold alloys (Vol. 294). Woodhead Pub Ltd.

[13] Prince A 1988 Critical assessment of copper-gold-silver ternary system. Int. Mater. Rev. 33 314-38.

[14] Chatterjee K, Howe J M, Johnson W C and Murayama M 2004 Static and in situ TEM investigation of phase relationships, phase dissolution, and interface motion in Ag-Au-Cu alloy nanoparticles Acta Mater. 52 2923-35.

[15] Nakagawa M and Yasuda K 1988 A coherent phase diagram of the Aux (Ag0. 24Cu0. 76) $1-x$ section of the Au- Cu- Ag ternary system $J$ Less Common Met. 138 95-106.

[16] Hamana D, Amiour L and Chetibi L 2009 The apparition of a new reaction at lower temperature in equiatomicCuAu alloy Phase Transitions.82 755-66.

[17] Maier A K, Tkalcec I, Mari D and Schaller R 2013 New In-Pd mechanical loss peak in ternary gold alloys Acta Mater.61 6107-13.

[18] Maier A K, Tkalcec I, Mari D and Schaller R 2013 Grain boundary formation stages in a deformed yellow gold single crystal studied by mechanical spectroscopy Mater. Sci. Eng, A. 560 466-72.

[19] Maier A K, Tkalcec I, Mari D and Schaller R 2012 Grain boundary relaxation and grain growth in 18-carat yellow gold alloy Scripta Mater.. 66 374-7.

[20] Hennig J, Mari D and Schaller R 2009 Stress-induced and atomic ordering in 18carat Au-Cu-Ag alloys Mater. Sci. Eng, A.521 47-51.

[21] Amiour L, Mermoul S and HamanaD 2014 Study of the Influence of Silver Addition on the Order-disorder Transformations in $\mathrm{Cu}-\mathrm{Au}$ System PhysProcedia. 55 30-4. 